\title{
PENGARUH MOTIVASI KERJA TERHADAP KEPUASAN KERJA PEGAWAI PADA KANTOR BADAN PERTANAHAN NASIONAL KABUPATEN TANGGAMUS PROVINSI LAMPUNG
}

\author{
Dedi Firdaus ${ }^{(1)}$, Hujaimatul Fauziah ${ }^{(2)}$, Iwan Zulfikar ${ }^{(3)}$ \\ Fakultas Ekonomi Universitas Sang Bumi Ruwa Jurai \\ firdaus_dedil@gmail.com,hujaimatul.fauziah@fe.saburai.ac.id,iwan.zulfikar@fe.saburai.ac.id
}

\begin{abstract}
Abstrak. Pegawai memerlukan motivasi untuk lebih giat dalam bekerja sehingga hasil pekerjaan menjadi lebih baik dan lebih tepat waktu Melihat pentingnya pegawai dalam organisasi, maka pegawai perlu lebih serius dalam melaksanakan tugasnya sehingga tujuan organisasi dapat tercapai. Obyek Penelitian adalah pengaruh motivasi kerja terhadap kepuasan kerja pegawai pada Kantor Badan Pertanahan Nasional Kabupaten Tanggamus Provinsi Lampung Adapun masalah yang ada pada kantor ini dirasakan pegawai yang merasa kepuasan masih sangat rendah, hal ini disebabkan karena sikap motivasi terhadap apa yang didapat. Tujuan Penelitian ini adalah untuk mengetahui pengaruh motivasi kerja terhadap kepuasan kerja pegawai pada Kantor Badan Pertanahan Nasional Kabupaten Tanggamus Provinsi Lampung.. Hipotesis yang diajukan dalam penelitian ini adalah "Kompensasi berpengaruh terhadap Kepuasan kerja Kantor Badan Pertanahan Nasional Kabupaten Tanggamus Provinsi Lampung". Pengumpulan data penelitian menggunakan teknik sampel penelitian dari 24 responden. Metode yang penulis gunakan menggunakan data primer dan data sekunder. Yang dilaksanakan dengan Penelitian Deskriptif. Dari persamaan regresi $Y=15,514+0,624 \mathrm{X}$ dan ini sesuai dengan hasil persamaan regresi bila Motivasi Kerja di tingkat satuan maka akan menghasilkan Kepuasan Kerja sebesar 0,624 satuan. dengan demikian hipotesis yang diajukan dapat diterima.
\end{abstract}

Kata kunci: Motivasi, Kepuasan Kerja, Pegawai.

\section{PENDAHULUAN}

Demi tercapainya tujuan organisasi, pegawai memerlukan motivasi kerja untuk lebih giat dalam bekerja sehingga hasil pekerjaan menjadi lebih baik dan lebih tepat waktu. Melihat pentingnya pegawai dalam organisasi, maka pegawai perlu lebih serius dalam melaksanakan tugasnya sehingga tujuan organisasi dapat tercapai. Dengan motivasi kerja yang tinggi, pegawai akan bekerja lebih giat didalam melaksanakan pekerjaannya. Sebaliknya dengan motivasi kerja yang rendah pegawai tidak mempunyai semangat dalam menyelesaikan pekerjaannya, mudah menyerah, dan memperoleh kesulitan dalam menyelesaikan pekerjaannya, kurang memiliki informasi yang jelas apakah pekerjaan mereka memiliki dampak positif terhadap para penerima manfaatnya yaitu individu atau kelompok yang dilayani organisasi.

Signifikansi tugas seringkali tidak pasti di organisasi - organisasi karena beberapa alasan. Pertama, pegawai di organisasi tersebut sering berpikiran yang buruk, yang membuat ragu apakah tujuan organisasi tersebut sudah tercapai. Kedua, para pegawai seringkali hanya menerima umpan balik langsung yang sedikit tentang bagaimana tindakan - tindakan mereka mempengaruhi penerima manfaat, yang mungkin membuat mereka ragu apakah misi mereka tercapai atau tidak.

Pengembangan sumber daya manusia merupakan unsur dan aset organisasi yang paling penting artinya semakin didasari bahwa manusia tidak boleh 
diperlakukan sebagai salah satu alat semata tetapi juga harus dianggap sebagai faktor yang amat vital berjalannya sebuah organisasi. Unsur-unsur manajemen terdiri dari manusia, alat-alat, perlengkapan metode, uang dan pasar, harus diterapkan secara terpadu dan harmonis sedemikian rupa sehingga tujuan yang ditetapkan dapat tercapai dengan ketentuan segala sesuatu berlangsung dalam batas waktu, usaha dan biaya yang ditetapkan.

Selain itu, organisasi perlu memperhatikan berbagai faktor yang dapat mempengaruhi motivasi pegawai, dalam hal ini diperlukan adanya peran organisasi dalam meningkatkan motivasi dan menciptakan lingkungan kerja yang kondusif guna mendorong terciptanya sikap dan tindakan yang profesional dalam menyelesaikan pekerjaan sesuai dengan bidang dan tanggung jawab masing masing.

Salah satu faktor yang mempengaruhi berjalannya program pada Kantor Badan Pertanahan Nasional Kabupaten Tanggamus Provinsi Lampung adalah kepuasan kerja pegawai pada instansi tersebut. Kepuasan kerja pegawai dapat diukur dengan persentase keberhasilan program yang dijalankan dengan yang ditargetkan.

\section{KAJIAN TEORI}

\section{Pengertian Motivasi}

Motivasi dapat ditafsirkan dan diartikan berbeda oleh setiap orang sesuai dengan tempat dan situasi dari masingmasing orang itu serta disesuaikan dengan perkembangan peradaban manusia. Namun ditinjau dari aspek taksonomi, motivasi berasal dari bahasa latin yaitu "movere" yang artinya bergerak. Menurut Winardi, dalam (2008: 1), istilah motivasi berasal dari perkataan bahasa latin, yakni movere yang berarti "menggerakkan" (to move). Dengan demikian secara etimologi, motivasi berkaitan dengan hal-hal yang mendorong atau menggerakan seseorang untuk melakukan sesuatu.

Harold Koontz dan Heinz Weihrich dalam (2008: 411) mengemukakan pendapatnya tentang motivasi sebagai berikut : "Motivation is a general trem applying to the entire class of drives, desire, needs, wishes and similar forces. To say that managers motivate their subordinates is to say that they do those things which they hope will satisfy these drives and desires and induce the subordinates to act in a desired manner".

Motivasi adalah suatu pengertian umum yang menggunakan seluruh kelas tentang dorongan, keinginan, kebutuhan, harapan dan kekuatan-kekuatan sejenisnya. Untuk mengatakan bahwa para manajer memotivasi bawahan mereka adalah dengan mengatakan bahwa mereka mengerjakan hal-hal yang mereka harapkan akan memuaskan dorongan dan keinginan ini dan mendorong bawahan untuk bertindak dengan suatu cara yang diinginkan. Dengan demikian maka istilah motif sama artinya dengan kata-kata motive, motif, dorongan, alasan dan lain-lain.

Sarwoto (2010:167) mengemukakan pengertian motivasi sebagai berikut : "Secara konkrit motivasi dapat diberikan batasan sebagai proses pemberian motif (penggerakkan) bekerja sebagai karyawan sedemikian rupa sehingga mereka mau bekerja dengan ikhlas demi tercapainya tujuan-tujuan organisasi secara efisien, memberi motivasi adalah pekerjaan yang dilakukan oleh seorang manajer dalam memberikan inspirasi, semangat kerja dan dorongan kepada orang lain untuk bekerja lebih baik."

Hal ini sejalan dengan pendapat Winardi (2009:40) yang menyatakan bahwa : "Motivasi berkaitan dengan kebutuhan. Kita sebagai manusia selalu mempunyai 
kebutuhan yang diupayakan untuk dipenuhi. Untuk mencapai keadaan termotivasi, maka kita harus mempunyai tindakan tertentu yang harus dipenuhi, dan apabila kebutuhan itu terpenuhi, maka muncul lagi kebutuhankebutuhan yang lain hingga semua orang termotivasi."

Dihubungkan dengan artikata asal motivasi tersebut menunjukan bahwa suatu motif merupakan keadaan kejiwaan yang mendorong atau menggerakan seseorang untuk bersikap dan berperilaku guna mencapai tujuan, baik individu maupun organisasi. Oleh karena itu secara garis besar dapat dikatakan bahwa motivasi setidaknya mengandung tiga komponen utama yakni kebutuhan, motif dan tujuan.

Menurut Victor H. Vroom (Ndraha, 2009:147) mengemukakan bahwa: "Motivasi adalah produk tiga faktor, Valence $(V)$, menunjukan seberapa kuat keinginan seseorang untuk memperoleh suatu reward, misalnya jika hal yang paling didambakan oleh seseorang pada suatu saat, promosi, maka itu berarti baginya promosi menduduki valensi tertinggi; Expectancy $(E)$, menunjukan kemungkinan keberhasilan kerja (performance probability). Probability itu bergerak dari 0 , (nol, tiada harapan) ke 1 (satu, penuh harapan). Instrumentality (I), menunjukkan kemungkinan diterimanya reward jika pekerjaan berhasil."

Sedangkan Atkinson (Zenzen, 2011:14) mengemukakan pendapatnya tentang motivasi sebagai berikut: "Motivational strength, according to Atkinson is a function of three variables which expressed as follows; Motivation $=f$ (motive $x$ expectancy $x$ incentive) the term of equation mean :

1. Motive refers to general dispotion of the individual to strive for the satisfaction of the need. It represent the urgency of the need for fulfilment.

2. Expectancy is the subjective calculation of the probability that a given act wills succehoped for by obtaining the goal.
3. Incentive is the subjective calculation of the value of the reward hoped for by obtaining the goal".

Kekuatan motivasi itu, menurut Atkinson adalah suatu fungsi dari tiga variabel yang dijelaskan sebagai berikut : Motivasi $=\mathrm{f}$ (motif $\mathrm{x}$ pengharapan $\mathrm{x}$ insentif). Adapun pengertian dari motif, pengharapan dan insentif yaitu:

Motif menunjukan kecenderungan yang umum dari individu untuk mendorong pemuasan kebutuhan. Ia mewakili kepentingan tentang pemenuhan kebutuhan.

Pengharapan adalah kalkulasi subyektif tentang kemungkinan tindakan tertentu yang akan berhasil dalam memuaskan kebutuhan (mencapai tujuan).

Menurut Sparrow dan Cooper (2013), adapun harapan karyawan dan organisasi sebagai berikut:

Harapan organisasi terhadap pekerja:

1. Bekerja sesuai dengan waktu yang telah disepakati

2. Melakukan pekerjaan yang maksimal/ berkualitas.

3. Jujur ketika berhubungan dengan klien

4. Loyal, menjaga reputasi organisasi;

5. Menggunakan properti perusahaan dengan hati-hati.

6. Berpenampilan dan berperilaku yang tepat

7. Lebih flexible terhadap job description

Harapan pekerja terhadap organisasinya :

1. Organisasi akan mengangkat pekerja dan memberikan pelatihan;

2. Organisasi meyakinkan pekerja akan bertindak adil dalam seleksi, rekruitmen, promosi dsb.

3. Organisasi bertindak adil dalam menjalankan semua aturan dan prosedur-prosedur yang berlaku; 
4. Organisasi memberikan upah yang sesuai dengan ketentuan yang berlaku.

5. Fair dalam pengalokasian keuntungan organisasi

6. Menyediakan waktu untuk berkumpul dengan keluarga dan memenuhi kebutuhan pribadi

7. Mengkonsultasikan dan mengkomunikasikan segala sesuatu yang membawa dampak pada pekerja

8. Meminimalkan campur tangan dalam hal bagaimana pekerja melakukan pekerjaannya

9. Memberikan dukungan personal untuk pekerjanya

10. Memberikan reward untuk kinerja yang maksimal.

11. Memberikan lingkungan kerja yang aman dan nyaman

12. Memberikan job security untuk pekerjanya

\section{METODE PENELITIAN}

\section{Objek Penelitian}

Objek penelitian ini adalah Kantor

Badan Pertanahan Nasional Kabupaten Tanggamus Provinsi Lampung, yang beralamatkan di Jl. Ahmad Yani Komplek Pemda Tanggamus Kota Agung. Data yang digunakan dalam penelitian ini adalah data dari tahun 2012 sampai tahun 2016 Sedangkan data diluar tahun tersebut tidak termasuk dalam penelitian. Pelaksanaan penelitian mulai bulan April sampai Agustus 2017.

\section{Metode dan Teknik Pengumpulan Data}

Dalam penelitian ini jenis data yang diperlakukan adalah :

a. Data Primer
Data primer merupakan data dasar yang akan diperoleh langsung tanpa perantara orang atau lembaga lain sebagai pihak ketiga. Data primer ini diperoleh dengan wawancara melalui responden dengan menggunakan daftar pertanyaan.

b. Data Sekunder

Data skunder merupakan data yang diperoleh melalui orang lain yang berhubungan dengan permasalahan yang dipecahkan. Data sekunder ini diperoleh melalui cara studi dokumenter yaitu mengumpulkan dan mempelajari brosurbrosur serta dokumen organisasi.

\section{Sampel dan Populasi}

Menurut Arikunto tentang pengambilan responden, apabila subjeknya kurang dari 100 lebih baik diambil semua, tetapi apabila subjeknya lebih dari 100 maka dapat diambil 10\%-15\% lebih baik (Arikunto, 2008 : 120). Responden yang digunakan adalah seluruh pegawai pada Kantor Badan Pertanahan Nasional Kabupaten Tanggamus Provinsi Lampung yaitu sebanyak 24 responden.

\section{Metode Analisis Data}

Untuk pengolahan data dalam bentuk tabulasi hasil jawaban responden kemudian dilakukan analisis data melalui metode analisis secara kualitatif dan analisa kuantitatif.

Analisis kualitatif merupakan analisis yang dinyatakan dalam bentuk uraian dan didasarkan pada data yang telah ada.Data kualitatif merupakan data berupa informasi yang kemudian dikaitkan dengan data lainnya sehingga memunculkan suatu kebenaran.

Analisis kuantitatif yang dilakukan berdasarkan data primer yang diperoleh dari penyebaran instrument (daftar pertanyaan) kepada sampel, dan untuk mengetahui pengaruh dari variabel bebas (independent 
variable) terhadap variabel terikat (dependent variable).

Persamaan Regresi Linear

Sederhana menentukan persamaan regresi linear sederhana untuk $\mathrm{X}$ :

$$
Y=a+b X+e
$$

Keterangan:

$$
\begin{aligned}
& \mathrm{Y}=\text { Kepuasan kerja } \\
& \mathrm{a}=\text { Konstanta } \\
& \mathrm{b}=\text { Koefisien regresi } \mathrm{X} \\
& \mathrm{X}=\text { Kompensasi } \\
& \mathrm{e}=\text { Faktor kesalahan }
\end{aligned}
$$

kemudian dilanjutkan dengan Rumus Koefisien Determinasi atau Koefisien Penentu (KP), untuk menentukan besar pengaruh:

$$
K P=(r)^{2} x 100 \%
$$

Untuk menguji secara hipotesis secara parsial digunakan Uji t dengan rumus :

$$
t_{\text {hitung }}=\frac{r \sqrt{N-2}}{\sqrt{1-r^{2}}}
$$

Keterangan:

$$
\begin{array}{ll}
\mathrm{t}_{\text {hitung }} & =\text { Nilai } \mathrm{t} \\
\mathrm{r} & =\text { Koefisien Korelasi } \\
\mathrm{N} & =\text { Jumlah responden }
\end{array}
$$

Kriteria untuk Uji $\mathrm{t}$ adalah sebagai berikut :

a) Jika $t_{\text {hitung }}>t_{\text {tabel }}$ maka Ha diterima dan Ho ditolak.

b) Jika $t_{\text {hitung }} \leq t_{\text {tabel }}$ maka Ha ditolak dan Ho diterima.

Taraf signifikan dalam penelitian ini digunakan $\alpha=0,05$ atau 5\%. Yang dimaksud dengan Hipotesis nol (Ho) dan Hipotesis alternatif (Ha) adalah :

Ho $=\mathrm{r} \leq 0=$ Berarti tidak ada pengaruhkompensasi kerja terhadap kepuasan kerja
$\mathrm{Ha}=\mathrm{r}>0 \quad=\quad$ Berarti ada pengaruh kompensasi kerja terhadap kepuasan kerja (Sugiyono, 2008).

Dalam hal ini diklasifikasikan ke dalam 3 kategori yaitu tinggi, sedang dan rendah.

Untuk membuat klasifikasi, sebelumnya dicari nilai interval terlebih dahulu dengan rumus :

Keterangan :

$$
\begin{gathered}
I=N T-\frac{N R}{K} \\
I=20-\frac{2}{3} \\
I=\frac{18}{3}
\end{gathered}
$$

I = Interval

$\mathrm{Nt} \quad=$ Nilai Tertinggi

$\mathrm{NR}=$ Nilai Terendah

$\mathrm{K}=$ Kategori

Responden dengan jawaban 2-6 :

Rendah

Responden dengan jawaban 7-11 :

Sedang

Responden dengan jawaban $12-20$ :

Tinggi

\section{HASIL DAN PEMBAHASAN}

Data penelitian yang telah dikumpulkan kemudian diolah untuk menguji kualitas data berupa uji validitas dan reliabilitas menunjukkan bahwa koefisien korelasi pearson moment untuk setiap item butir pertanyaan dengan skor total variabel kompensasi (X), dan kepuasan kerja (Y) signifikan pada tingkat signifikan $\alpha$ 0,05. Dengan demikian dapat diinterprestasikan bahwa setiap item indikator instrumen masing-masing variabel tersebut valid.

\section{Uji Validitas}


Tabel . Jawaban Responden Tentang Kepuasan Kerja

\begin{tabular}{|l|l|l|l|}
\hline No & $\begin{array}{l}\text { Alternatif } \\
\text { Jawaban }\end{array}$ & Frekuensi & $\%$ \\
\hline 1 & Rendah 2-6 & 2 & $4,55 \%$ \\
\hline 2 & Sedang 7-11 & 2 & $4,55 \%$ \\
\hline 3 & $\begin{array}{l}\text { Tinggi 12- } \\
20\end{array}$ & 20 & $90,9 \%$ \\
\hline & Jumlah & 24 & $100 \%$ \\
\hline
\end{tabular}

Sumber :Kantor Badan Pertanahan Nasional Kabupaten Tanggamus Provinsi Lampung, 2017

Berdasarkan tabel 1tentang kepuasan kerja tinggi $(90,9 \%)$, sedang $(4,55 \%)$, dan rendah $(4,55 \%)$ dari 24 responden. Dengan demikian disimpulkan bahwa kepuasan kerja sudah cukup baik dan perlu ditingkatkan lagi.

Dengan menggunakan rumus korelasi product moment dengan taraf signifikan 5\%, maka dapat nilai :

$$
\begin{aligned}
& r_{x y}=\frac{24 \times 31248-1164 \times 117}{\sqrt{\left\{35 \times 30954-(1164)^{2}\right\}\left\{35 \times 31734-(1176)^{2}\right\}}} \\
& r_{x y}=\frac{1374912-1370028}{\sqrt{\{131976-1354890\}\{1398540-1385329\}}} \\
& r_{x y}=\frac{4984}{\sqrt{(7086)(13211)}} \\
& r_{x y}=\frac{4984}{9675}=0,5114
\end{aligned}
$$

Dengan demikian karena $r$ hitung lebih besar dari $r$ tabel, maka dapat dikatakan bahwa pengaruh motivasi kerja terhadap kepuasan kerja pegawai pada Kantor Badan Pertanahan Nasional Kabupaten Tanggamus Provinsi Lampung berpengaruh positif.

\section{Uji Reliabilitas Data}

Uji reliabilitas instrumen menggunakan rumus Cronbach Alpha $(\alpha)$ untuk masing-masing variabel adalah lebih besar dari 0,60. Demikian dapat disimpulkan bahwa item-item untuk masing-masing variabel adalah reliabel.Nilai reliabilitas konsistensi internal ditunjukkan dalam tabel diatas , untuk koefisien Alpha Cronbach dinyatakan reliabel karena lebih besar dari 0,60 . Dengan demikian item pengukuran pada masing-masing indikator dalam variabel-variabel penelitian dinyatakan reliabel dan selanjutnya dapat digunakan dalam penelitan.

\section{Analisis Kuantitatif}

Untuk mengetahui besarnya pengaruh antara motivasi kerja terhadap kepuasan kerja dapat dihitung dengan rumus Koefisien Determinasi (KD). Dengan demikian hubungan antara motivasi kerja terhadap kepuasan kerja pada Kantor Badan Pertanahan Nasional Kabupaten Tanggamus Provinsi Lampung dapat digunakan rumus Koefisien Determinasi (KD), yaitu:

$$
\begin{gathered}
K D=r^{2} \times 100 \% \\
=0,51142^{2} \times 100 \% \\
=0,2615 \times 100 \% \\
=26,15 \%
\end{gathered}
$$

Dengan demikian motivasi kerja terhadap kepuasan kerja pada Kantor Badan Pertanahan Nasional Kabupaten Tanggamus Provinsi Lampung mempunyai pengaruh $26,15 \%$ dan sisanya sebesar $75,85 \%$ dipengaruhi oleh faktor lain.

\section{KESIMPULAN DAN SARAN}

\section{Kesimpulan}

Berdasarkan hasil penelitian dan pembahasan yang sudah dilakukan maka dapat disimpulkan sebagai berikut :

Nilai koefisiensi determinasi (R2) variabel motivasi kerja terhadap kepuasan kerja pegawai sebesar 0,476. Hal ini menunjukkan bahwa pengaruh motivasi kerja terhadap kepuasan kerja pegawai sebesar 47,6\% dan sisanya dipengaruhi oleh faktor lain. Dari analisis diperoleh koefisien korelasi atau $t_{\text {hitung }}=5,136$ sedangkan $t_{\text {tabel }}$ 
dengan taraf signifikan 1,690 dengan demikian thitung lebih besar dari tabel 5,136 > 1,690. Hal ini menunjukkan motivasi kerja mempunyai hubungan yang signifikan terhadap kepuasan kerja.

Untuk mengetahui analisis tersebut, maka dapat diketahui dengan menggunakan koefisien penentu $\left(\mathrm{r}^{2}\right)$ dengan nilai $47,60 \%$, dengan ini motivasi kerja mempunyai pengaruh terhadap kepuasan kerja pegawai pada Kantor Badan Pertanahan Nasional Kabupaten Tanggamus Provinsi Lampung sebesar 47,60\%, sedangkan selebihnya dipengaruhi oleh faktor lain yang tidak diteliti.

Berdasarkan analisis dengan menggunakan Koefisien Determinasi (KD) berarti terdapat pengaruh yang positif dan signifikan antara motivasi kerja dengan kepuasan kerja pegawai pada Kantor Badan Pertanahan Nasional Kabupaten Tanggamus Provinsi Lampung.

\section{Saran}

Adapun saran yang diajukan peneliti adalah sebagai berikut:

1. Hendaknya pegawai pada Kantor Badan Pertanahan Nasional Kabupaten Tanggamus Provinsi Lampung lebih meningkatkan lagi motivasi kerja nya dengan cara menanamkan rasa memiliki lingkungan kerjanya dan rasa tanggung jawab terhadap tugas yang diberikan kepadanya.

2. Hendaknya pegawai pada Kantor Badan Pertanahan Nasional Kabupaten Tanggamus Provinsi Lampung lebih meningkatkan kinerjanya yang dapat memberikan kepuasan dalam bekerja.

\section{DAFTAR PUSTAKA}

Arikunto, Suharsimi. 2002. Prosedur Penelitian (Suatu Pendekatan Praktek). Jakarta: Rineka Cipta.
Anoraga, Pandji. 2009. Manajemen Bisnis. Jakarta: Rineka Cipta.

Dwiyanto, Agus.2005. Mewujudkan Good Governance melalui Pelayanan Publik. Yogyakarta: Gajah Mada Press.

Handoko, T. Hani. 1999. Manajemen Edisi kedua. Yogyakarta: BPFE.

Irawan, .2002. Manajemen Personalia. Yogyakarta:BPFE.

Istiyanto, 2006. Riset Sumberdaya Manusia. Jakarta: PT. Gramedia Pustaka Utama.

Luthans, Fred. 2006. Perilaku Organisasi. Yogyakarta: Andi.

Malthis, R. L., dan J.H. Jackson. 2006. Manajemen Sumber Daya Manusia buku 1 dan buku 2. Jakarta: Salemba Empat.

Mangkunegara, A. A. Anwar Prabu. 2004. Evaluasi Kinerja Sumber Daya Manusia.Bandung:Refika Aditama.

Manullang, 2001. Manajemen Sumber Daya Manusia (cetakan pertama). Yogyakarta:BPFE.

Malayu, S.P.Hasibuan. 2003. Organisasi dan Motivasi. Jakarta : Bumi Aksara.

Moenir, H.A.S. 2001. Manajemen Pelayanan Umum di Indonesia. Jakarta: Bina Aksara.

Malayu, S.P.Hasibuan. (2001). Manajemen Sumber Daya Manusia.. Jakarta: Cetakan IV Bumi Aksara. 
Dedi Firdaus : Pengaruh Motivasi Kerja Terhadap Kepuasan Kerja Pegawai Pada Kantor Badan Pertanahan Nasional Kabupaten Tanggamus Provinsi Lampung

Moh. Nazir, (2005). Metode Penelitian cetakan IV. Jakarta: Ghalia Indonesia. 